\title{
Primate Population Dynamics Over 32.9 Years at Ngogo, Kibale National Park, Uganda
}

\author{
J.S. LWANGA ${ }^{1}$, T.T. STRUHSAKER ${ }^{2 *}$, P.J. STRUHSAKER ${ }^{3}$, T.M. BUTYNSKI ${ }^{4}$, AND J.C. MITANI ${ }^{5}$ \\ ${ }_{1}^{1}$ Institute of Environment and Natural Resources, Makerere University, Kampala, Uganda; and Makerere University Biological \\ Field Station, Fort Portal, Uganda \\ ${ }^{2}$ Department of Evolutionary Anthropology, Duke University, Durham, North Carolina \\ ${ }^{3} 1563122_{e}$ Rue, Mirabel, Quebec, Canada \\ ${ }^{4}$ King Khalid Wildlife Research Centre, Riyadh, Kingdom of Saudi Arabia \\ ${ }^{5}$ Department of Anthropology, University of Michigan, Ann Arbor, Michigan
}

We present census data for eight primate species spanning 32.9 years along the same transect at Ngogo, Kibale National Park, Uganda, demonstrating major changes in the composition of the primate community. Correlated with an estimated decline of $\sim 89 \%$ in the red colobus population was an increase in encounter rates with chimpanzee parties. Our data, along with the unusually high rates of predation by chimpanzees on red colobus at Ngogo and the fact that the chimpanzee community at Ngogo is the largest ever recorded, support the conclusion that the red colobus decline was caused primarily by chimpanzee predation. This seems to be the first documented case of predation by one nonhuman primate causing the population decline in another. We evaluated disease and interspecific competition as other possible causes of the red colobus decline, but judged them to be relatively insignificant compared with predation by chimpanzees. Notable changes in encounter rates with other primate species may have resulted from forest expansion. Those for mangabeys, redtails, and black and white colobus increased significantly. Encounter rates increased for l'Hoest's monkeys too, but the increased sightings may have been an artifact of increased habituation. Sightings of blue monkey and baboon groups declined. There was no significant change in encounter rates for all species combined. The Ngogo primate community seemed to be in a nonequilibrium state, changing from one dominated by two species, a folivore (red colobus) and a frugivorous omnivore (redtails), to one dominated by three species of frugivorous omnivores (redtails, mangabeys, and chimpanzees). This study demonstrates the importance of long-term monitoring in understanding population dynamics and the role of intrinsic variables in shaping the species composition of a community. Am. J. Primatol. 73:997-1011, 2011. (c) 2011 Wiley-Liss, Inc.

\section{Key words: red colobus; chimpanzee predation; population dynamics; community ecology; Kibale National Park}

\section{INTRODUCTION}

An understanding of population dynamics is critical to the development of effective conservation management plans and realistic models of population and behavioral ecology. Long-term studies indicate that some and perhaps most primate populations are in nonequilibrium states [e.g. Chapman et al., 2010; Struhsaker, 2008]. There are numerous examples of population declines among primates, often the result of habitat loss and/or overhunting by humans, e.g. Procolobus badius waldroni, Cercopithecus diana roloway, and Cercocebus atys lunulatus [McGraw, 2007; Oates et al., 2000; Struhsaker, 1997, 1999, 2005; Struhsaker \& Oates, 1995], Procolobus gordonorum [Struhsaker et al., 2004], and Procolobus r. rufomitratus [Mbora \& Meikle, 2004]. Less well understood are declines in primate populations caused by nonanthropogenic factors, such as those in red howler monkeys, where the causes of the declines were never determined, but speculated to be disease and/or drought-induced food shortage (Alouatta seniculus) [Pope, 1998; Rudran \& Fernandex-Duque, 2003].

Here, we report significant changes in the populations of eight sympatric anthropoid species

\footnotetext{
This article was published online on 9 May 2011. Subsequently errors were identified and the article was corrected on 19 May 2011.

Contract grant sponsors: New York Zoological Society and the African Wildlife Foundation; U.S. National Science Foundation; Contract grant numbers: SBR-9253590; BCS-0215622; IOB0516644

*Correspondence to: T.T. Struhsaker, 2953 Welcome Drive, Durham, NC 27705. E-mail: tomstruh@duke.edu

Received 13 July 2010; revised 12 April 2011; revision accepted 13 April 2011

DOI 10.1002/ajp.20965

Published online 9 May 2011 in Wiley Online Library (wileyonlinelibrary.com).
} 
at Ngogo in Kibale National Park, a site that is well protected against poaching and habitat disturbance by humans. The most prominent change was in the red colobus monkeys (Procolobus rufomitratus tephrosceles). Mitani et al. [2000] reported a statistically significant decline in abundance of red colobus at Ngogo of $\sim 43.4 \%$ between the censuses of 1975-1976 and those of 1997-1998. Teelen [2005, 2007] later compared her 2001-2002 census data from this same transect with those collected by T. Struhsaker (1975-1976), Butynski (1978-1984), and Lwanga (1997-1998, 2002-2003). Although Teelen [2007] did not test for statistical differences between these five census periods, encounter rates with red colobus in 2002-2003 were $\sim 88.7 \%$ lower than in 1975-1976.

Our study adds to these earlier reports in several ways. First, we add nine more years of census data. Second, rather than just comparing the mean values of census periods that varied in duration from one to several years and often with long breaks between them, we present the data in more detail. Our analyses provide greater resolution, allowing one to better distinguish between changes in abundance that were owing to unidirectional trends, short-term cycles, episodic events, or the fluctuations resulting from high intercensus variation often associated with less common species. Third, with more detailed analyses, we are better able to identify the temporal pattern of change and identify possible causal factors. Fourth, our data extend through 2007, four more years beyond those presented by Teelen [2007], thereby expanding our understanding of the longterm trends in abundance for these eight species. Fifth, we evaluate data on group sizes within each of the four species over most of this sample period, thereby providing information critical to interpreting the census results. Sixth, we consider more possible causes of the red colobus decline than any of the previous studies. Seventh, we demonstrate enormous changes in home range size of red colobus groups over this sample period that corresponds with changes in abundance. Eighth, we integrate dietary data with tree population dynamics to better understand the decline of red colobus. Ninth, we demonstrate a significant negative correlation between encounter rates of red colobus and chimpanzees. Tenth, we give greater consideration to all eight anthropoid species, not just the red colobus and blue monkeys (Cercopithecus mitis). Finally, we analyzed the long-term census data using statistical tests, which were not previously done for any species after the 1998 census period.

Our study demonstrates the role of intrinsic biological variables in population dynamics and why effective conservation requires more than simply protecting an area against human activities. Longterm biological monitoring is crucial for documenting community population dynamics and evaluating the intrinsic variables that may be causing these changes.

\section{METHODS}

\section{Study Site and Subjects}

We conducted primate censuses at the Ngogo study site in Kibale National Park $\left(766 \mathrm{~km}^{2}\right)$, Uganda $\left(0^{\circ} 13^{\prime}-0^{\circ} 41^{\prime} \mathrm{N}\right.$ and $\left.30^{\circ} 19^{\prime}-30^{\circ} 32^{\prime} \mathrm{E}\right)$. Vegetation in the study area consists of old-growth, moist, evergreen tropical forests interspersed with grassland, scrub, and colonizing forest. Detailed descriptions of the study site are in Ghiglieri [1984], Butynski [1990], Struhsaker [1997], and Lwanga et al. [2000]. Our study included all eight diurnal primate species occurring at Ngogo. These were black and white colobus (Colobus guereza occidentalis), red colobus (P. rufomitratus tephrosceles), olive baboons (Papio anubis), grey-cheeked mangabeys (Lophocebus albigena johnstoni), blue monkeys (C. mitis stuhlmanni), redtail monkeys (Cercopithecus ascanius schmidti), l'Hoest's monkeys (Cercopithecus lhoesti), and chimpanzees (Pan troglodytes schweinfurthii). All these species, except baboons and redtails, are of conservation concern throughout most of their ranges because of habitat loss and overhunting.

\section{Field Methods}

We collected data using line transect methods [National Research Council, 1981; Struhsaker, 1997; Whitesides et al., 1988] along the same transect located in old-growth forest in the middle of the Ngogo study site. This transect, referred to as the main census transect, follows an approximate square configuration along trails $4, \mathrm{~F}, 10$, and $\mathrm{K}$ with parallel trails being separated by $\sim 1 \mathrm{~km}$ [see Fig. 1 in Mitani et al., 2000, and Fig. 1 in Lwanga, 2006]. Most of this transect runs through old-growth forest. Visibility and sighting distance along this transect did not change in any obvious way over the entire study, as evidenced by the consistency in sighting distances of T. Struhsaker between 1975-1976 and 1996 [Mitani et al., 2000]. At the beginning of our study, the transect encircled and came within $100-250 \mathrm{~m}$ of a $\sim 50$ ha grassland. This grassland was last burned in January 1991 and, with the prevention of fire over subsequent years, it was completely colonized by young forest [Lwanga, 2003]. Each of our censuses for 1975-1984 covered $4.03 \mathrm{~km}$, whereas those for 1985-2007 covered a slightly longer distance of $4.4 \mathrm{~km}$ on the same transect.

All observers used identical methods. Censuses began at approximately $07: 30 \mathrm{hr}$ and ended at around 12:30-13:30 hr, depending on the number of primate groups encountered. We walked at $\sim 1 \mathrm{~km}$ per hour, pausing at regular intervals to scan the forest and listen for calls and movements in the canopy. When a primate was sighted, the observer stopped for $\sim 10 \mathrm{~min}$ to record the species present, time, location, number of visible individuals, and several other variables not relevant to this report. 
To minimize detection biases influenced by time of day, each observer varied the direction of travel along the census route on successive censuses.

The observations reported here encompass a 32.9-year period, beginning January 1975 when T. Struhsaker began systematic censuses of diurnal primates along the $4.03 \mathrm{~km}$ long transect at Ngogo. This resulted in 24 surveys during a 1.87-year period, ending November 1976. After a hiatus of 2 years, Butynski made 16 surveys along the same transect between November 1978 and May 1980 and another 28 surveys between June 1981 and September 1984, encompassing a period of 5.8 years. Lwanga conducted 16 censuses from April through December 1985. Following a break of 10.6 years, censuses along the $4.4 \mathrm{~km}$ transect were resumed when, during a brief return visit to Ngogo, it appeared to T. Struhsaker that the red colobus population had drastically declined. To verify this impression, he conducted 16 censuses during a 3 -week period in July 1996. Later that year, Mitani conducted another 10 censuses ( 2 per month) from August through December 1996. Beginning in January 1997, Lwanga conducted two censuses every month through 2007, totaling 262 censuses.

The censuses were equally distributed among all months of the year for the census periods of 1997-2007, representing 70\% of the entire sample. During the remaining sample periods, censuses were conducted in both wet and dry seasons approximately in proportion to the duration of these seasons, as defined by long-term rainfall data [Struhsaker, 1997; p 25]. Rainfall was usually low during 5 months (42\%) of the year (the dry season), much greater during 6 months (50\%) (wet season), and transitional in one (8.3\%). Seasonal distribution of the censuses was as follows:

1. $1975-1976$ : $46 \%$ in dry and $54 \%$ in wet months.

2. $1978-1984$ : $41 \%$ in dry, $48 \%$ in wet, and $11 \%$ in transitional months.

3. 1985: $31 \%$ in dry, $56 \%$ in wet, and $13 \%$ in transitional months.

It is important to emphasize that seasonality in Kibale is not well pronounced in terms of rainfall or tree phenology [Struhsaker, 1997]. Given these facts and the temporal distribution of the censuses, we conclude that seasonality is unlikely to have biased our results.

Although the DISTANCE program is often advocated as an accurate means of estimating population densities of primates [Buckland et al., 2010], we chose not to use it because numerous studies have demonstrated that this method usually overestimates densities of forest primate groups, often by twofold or more, when compared with the most accurate estimates of density that are based on detailed studies of specific social groups [e.g. Chapman et al., 2010; Ferrari et al., 2010;
National Research Council, 1981; Struhsaker, 1997, 2002, 2010]. In addition, the DISTANCE method makes a number of assumptions that are often not met by line transect censuses of primates [Marshall et al., 2008] and the use of perpendicular distance, as required by DISTANCE, underestimates the area sampled [Struhsaker, 1997, see detailed critique in Struhsaker, 2010].

We did not attempt to estimate primate densities, because the accuracy of density estimates based on census transect data is determined by the accuracy of sighting distances, and we were unable to compare interobserver reliability in estimating sighting distances among ourselves because we were in the field at different times. Mitani et al. [2000] found that estimates of sighting distances could differ significantly among observers at Ngogo, but that these same observers did not differ from one another in the number of primate groups they saw. Instead of estimating densities, we used sighting frequencies or encounter rates of primate social groups, i.e. the number of groups (a cluster of conspecifics) sighted per kilometer of each census. We interpret this measure as indicating abundance after Mitani et al. [2000], as derived from Caughley [1980] [also see Chapman et al., 2000; Kuhl et al., 2008; Lwanga, 2006; Rovero \& Struhsaker, 2007; Teelen, 2007]. This method provides an index of abundance that avoids the assumptions of the DISTANCE program and the problems associated with comparing estimations of distance between different observers. In making comparisons, we assumed that all observers were equally adept at detecting primate groups. Indeed, interobserver agreement in detection of primate groups was high between T. Struhsaker and Butynski and between T. Struhsaker and Lwanga [unpublished observation]. Solitary monkeys were not included in this analysis because they were not commonly seen.

Estimates of chimpanzee abundance are often obtained through nest counts [e.g. Ghiglieri, 1984; Kuhl et al., 2008]. Here, we used direct counts of animals sighted and, following Mitani et al. [2000], we included counts of both solitary animals as well as parties of chimpanzees in the analyses, because chimpanzees live in fission-fusion societies and are usually dispersed in the canopy and on the forest floor, making it difficult to ascertain if single chimpanzees are in association with other chimpanzees [Mitani et al., 2000].

\section{Analytical Methods}

The raw data for all species consist of integer values with Poisson distributions. To account for differences in census lengths, the total number of group sightings for each species and every census were standardized as mean encounters (sightings) per kilometer. We partitioned these data into 
16 census periods: 1975 (Struhsaker, 1975-1976, $N=24) ; 1979$ (Butynski, 1978-1980, $N=16$ ); 1983 (Butynski, 1981-1984, $N=28$ ); 1985 (Lwanga, 1985, $N=16$ ); 1996 (Struhsaker and Mitani, 1996, $N=26$ ); 1997 through 2007 (Lwanga annual results, $N=24$ for each year from 1997 to $2005 ; N=23$ for each year from 2006-2007). The total number of censuses for all periods is 372. Mean encounter rates and their 95\% confidence intervals were calculated for each species for each of these census periods.

The precision of group encounters is the 95\% confidence limits of estimated means expressed as the percentage of these means [National Research Council, 1981]. When the precision of group encounters reaches an asymptote, one may conclude that sufficient repetitions have been completed to provide a representative sample for a given time period on a given transect. The number of repetitions needed varies among transects and species. On the Ngogo transect, precision curves reached an asymptote after $15-20$ census repetitions, particularly so for the more common species, e.g. red colobus, redtails, mangabeys, and chimpanzees, but also during some census periods for the blue monkeys, which was the least common species [Lwanga, 2006; Mitani et al., 2000]. Because more than 15 repetitions were completed for each census period, we concluded that our samples are representative and large enough to detect differences.

We obtained a smoothing function that modeled fluctuations in encounter rates with species over time by calculating nonparametric regressions of these encounter rates using locally weighted regressions, i.e. Lowess curves as described by Ruskeepää [2009]. We found that iterative trial fits of the data using 20 weighted linear least squares regressions $(\lambda=1)$ minimized the local fit of the squared residuals to near zero using a value of $\alpha=0.4$ for all species, as evaluated by the local residuals plot module given by Ruskeepää [2009]. We calculated regressions separately for the first 84 and last 288 censuses, i.e. before vs. after the 10-year gap in observations.

The primary step in analyzing a time series, which our observations represent, is to use ordinary least squares regressions to test for long-term secular trends [Kachigan, 1986]. These linear regressions provide primary evidence of long-term change (nonzero slopes) and strength of the data, and thus permit inferences about long-term group encounter rates along the census transect; however, they should not be construed as modeling changes in encounter rates over time. Owing to the Poissson distribution of the original variates, i.e. encounter rates which consist of many zeros, we calculated first-degree regressions with square root transformations of the data after adding 0.5 to all standardized group encounter data [Sokal \& Rohlf, 1995; p 415]. Comparisons of studentized residuals of untrans- formed and transformed regressions for all species, as well as comparison of the probabilities and $r$-squared values, show only small and inconsequential differences between data sets $(<1.0 \%)$. The resulting regression equations of the transformed data are given in Table I and were back-transformed for representation in Figures 1-9. We note that the Gauss-Markov theorem for least squares analysis does not require normal errors (distribution), but does require homoscedasticity, which is exhibited by all of our regression sets.

As additional evidence to support or reject the positive and negative secular trends exhibited by the eight species, we calculated $t$-tests with the transformed data and tested the first 84 censuses (1975-1985) against the last 288 (1996-2007). We also conducted Spearman rank correlation tests of encounter rates and corresponding census number (i.e. 1-372). We estimated overall percentage changes in encounter rates for each species by comparing the differences between the mean encounter rates for the 1975-1976 census period $(n=24)$ with those for the 2007 period $(n=23)$ (Table I).

This research adhered to the legal requirements of Uganda and to the American Society of Primatologists Principles for the Ethical Treatment of Nonhuman Primates. It was approved by the University Committee on the Use and Care of Animals (UCUCA), University of Michigan under UCUCA Research Applications 6793A, 7472, 8436, and 9035 .

\section{RESULTS \\ Changes in Encounter Rates With Groups}

Patterns of change in encounter rates differed for the eight study species, and were most apparent when data for the two major sample periods were compared, i.e. 1975-1985 vs. 1996-2007 (Figs. 1-9 and Table I). The $t$-values for the linear trend lines were significant for all species. The low $r^{2}$ values reflect the great variation in encounter rates even within a census period (Table I). We emphasize that these low $r^{2}$ do not relate to the statistical significance of the trend line, but simply indicate that factors in addition to the sequential order of the census are affecting the variance in encounter rates. Spearman rank correlation tests were generally consistent with the linear trend results, except for black and white colobus and redtails (Table I). When all species were combined, group-encounter rates showed no significant change over the entire period (Fig. 9 and Table I).

Group encounter rates for red colobus declined significantly over the 32.9 years, with a difference of $88.8 \%$ between the mean encounter rates of the 1975-1976 censuses and those of 2007 (Fig. 1 and Table I). Based on the mean values for each census 


\begin{tabular}{|c|c|c|c|c|}
\hline Species & $\begin{array}{c}\text { Linear trend line of } \\
\text { transformed data } \\
\text { for census days } 1-12,029 \\
(1975-2007)^{\mathrm{a}}\end{array}$ & $\begin{array}{l}\text { Spearman rank } \\
\text { correlation for } \\
\text { censuses } 1-372\end{array}$ & $\begin{array}{c}t \text {-test (transformed } \\
\text { data) } \\
1975-1985 \\
(N=84) \text { vs. } \\
1996-2007 \\
(N=288)\end{array}$ & $\begin{array}{l}\text { Mean total encounters } \\
\text { per kilometer } \\
\text { for } 1975-1976 \text { and } \\
2007 \text { census periods } \\
\text { and percentage change }\end{array}$ \\
\hline Black and white colobus & $\begin{array}{c}t \text {-value }=1.899 \\
P=0.058 \\
\hat{y}=0.730+2.2 \times 10^{-6} \times \\
r^{2}=0.0097\end{array}$ & $\begin{array}{c}r=0.072 \\
t \text {-value }=1.387 \\
P=0.166\end{array}$ & $\begin{array}{c}t \text {-value }=-2.37 \\
P=0.019\end{array}$ & $\begin{array}{c}1975-1976=0.031 \\
2007=0.0988 \\
219 \%\end{array}$ \\
\hline Red colobus & $\begin{array}{c}t \text {-value }=-13.07 \\
P<1.0 \times 10^{-16} \\
\hat{y}=1.01-0.00002 \times \\
r^{2}=0.316\end{array}$ & $\begin{array}{c}r=-0.590 \\
t \text {-value }=-14.05 \\
P<1.0 \times 10^{-16}\end{array}$ & $\begin{array}{c}t \text {-value }=8.43 \\
P=2.0 \times 10^{-13}\end{array}$ & $\begin{array}{c}1975-1976=0.527 \\
2007=0.0593 \\
-89 \%\end{array}$ \\
\hline Baboon & $\begin{array}{c}t \text {-value }=-2.382 \\
P=0.018 \\
\hat{y}=0.769-2.5 \times 10^{-6} \times \\
r^{2}=0.015\end{array}$ & $\begin{array}{c}r=-0.116 \\
t \text {-value }=-2.255 \\
P=0.025\end{array}$ & $\begin{array}{c}t \text {-value }=2.090 \\
P=0.039\end{array}$ & $\begin{array}{c}1975-1976=0.103 \\
2007=0.0395 \\
-62 \%\end{array}$ \\
\hline Grey-cheeked mangabey & $\begin{array}{c}t \text {-value }=4.413 \\
P=0.00001 \\
\hat{y}=0.788+7.8 \times 10^{-6} \times \\
r^{2}=0.050\end{array}$ & $\begin{array}{c}r=0.191 \\
t \text {-value }=3.74 \\
P=0.0002\end{array}$ & $\begin{array}{c}t \text {-value }=-3.09 \\
P=0.002\end{array}$ & $\begin{array}{c}1975-1976=0.165 \\
2007=0.376 \\
127 \%\end{array}$ \\
\hline Blue monkey & $\begin{array}{c}t \text {-value }=-3.763 \\
P=0.0002 \\
\hat{y}=0.748-2.7 \times 10^{-6} \times \\
r^{2}=0.037\end{array}$ & $\begin{array}{c}r=-0.141 \\
t \text {-value }=-2.748 \\
P=0.006\end{array}$ & $\begin{array}{c}t \text {-value }=3.040 \\
P=0.003\end{array}$ & $\begin{array}{c}1975-1976=0.0931 \\
2007=0.0297 \\
-68 \%\end{array}$ \\
\hline Redtail monkey & $\begin{array}{c}t \text {-value }=2.649 \\
P=0.008 \\
\hat{y}=0.974+6.1 \times 10^{-6} \times \\
r^{2}=0.019\end{array}$ & $\begin{array}{c}r=0.087 \\
t \text {-value }=1.677 \\
P=0.094\end{array}$ & $\begin{array}{c}t \text {-value }=-2.47 \\
P=0.014\end{array}$ & $\begin{array}{c}1975-1976=0.455 \\
2007=0.702 \\
54 \%\end{array}$ \\
\hline l'Hoest's monkey & $\begin{array}{c}t \text {-value }=3.935 \\
P=0.0001 \\
\hat{y}=0.708+3.7 \times 10^{-6} \times \\
r^{2}=0.040\end{array}$ & $\begin{array}{c}r=0.212 \\
t \text {-value }=4.18 \\
P=0.00004\end{array}$ & $\begin{array}{c}t \text {-value }=-3.66 \\
P=0.0003\end{array}$ & $\begin{array}{c}1975-1976=0.0207 \\
2007=0.109 \\
426 \%\end{array}$ \\
\hline Chimpanzee & $\begin{array}{c}t \text {-value }=4.546 \\
P=7.0 \times 10^{-6} \\
\hat{y}=0.753+7.9 \times 10^{-6} \times \\
r^{2}=0.050\end{array}$ & $\begin{array}{c}r=0.178 \\
t \text {-value }=3.47 \\
P=0.0006\end{array}$ & $\begin{array}{c}t \text {-value }=-5.26 \\
P=4.0 \times 10^{-7}\end{array}$ & $\begin{array}{c}1975-1976=0.155 \\
2007=0.237 \\
53 \%\end{array}$ \\
\hline Total species & $\begin{array}{c}t \text {-value }=0.106 \\
P=0.92 \\
\hat{y}=1.36+3.8 \times 10^{-7} \times \\
r^{2}=0.00003\end{array}$ & $\begin{array}{c}r=0.034 \\
t \text {-value }=0.651 \\
P=0.52\end{array}$ & $\begin{array}{c}t \text {-value }=0.16 \\
P=0.87\end{array}$ & $\begin{array}{c}1975-1976=1.551 \\
2007=1.635 \\
5 \%\end{array}$ \\
\hline
\end{tabular}

${ }^{\mathrm{a}} t$-values and associated $P$-values are from tests of the null hypothesis that the slope equals zero. All $P$-values are two-tailed.

period, the decline in sightings of red colobus was consistent over time without obvious oscillations or fluctuations, becoming clearly apparent by 1985 . We do not know what happened to the Ngogo red colobus subpopulation between 1986 and 1995, but in 1996 the decline in sightings of them continued until about 2003, at which time sightings reached an asymptote or possibly began to increase slightly (Fig. 1). Relevant here is the significant negative correlation between sightings of red colobus and chimpanzees during the 372 censuses $\left(r_{\mathrm{s}}=-0.127\right.$, $P=0.007, \mathrm{df}=370$ ).

Although less dramatic, encounter rates with chimpanzees also changed, but in their case, they increased significantly (Table I and Fig. 2). Aside from the dip in encounter rates during the 1978-1980 census period and peaks in 2000 and 2002-2003, the increase in encounter rates with chimpanzees was consistent over time. Some of this fluctuation between census periods may be the result of the variability between individual censuses owing to the relatively low density of chimpanzees and their large home range.

Encounter rates with groups of black and white colobus, mangabeys, redtail, and l'Hoest's monkeys all increased significantly, whereas those for blue monkeys and baboons decreased significantly (Figs. 3-8 and Table I). 


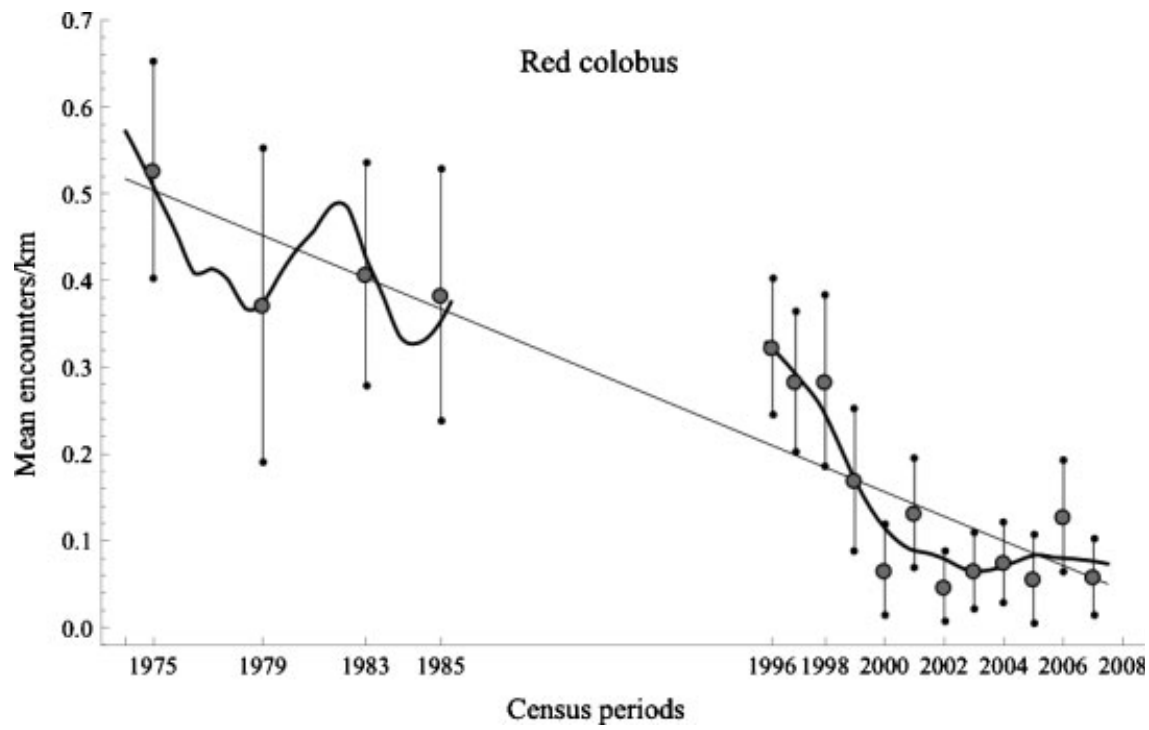

Fig. 1. Red colobus population change. Linear trend line (straight line); locally weighted regression (Lowess curve, black irregular line); mean counts/kilometer for each census period (closed gray circles); limits of 95\% confidence intervals of means (vertical lines and small black closed circles). The abscissa tick marks indicate midpoints of census periods; first tick indicates day one of the censuses.

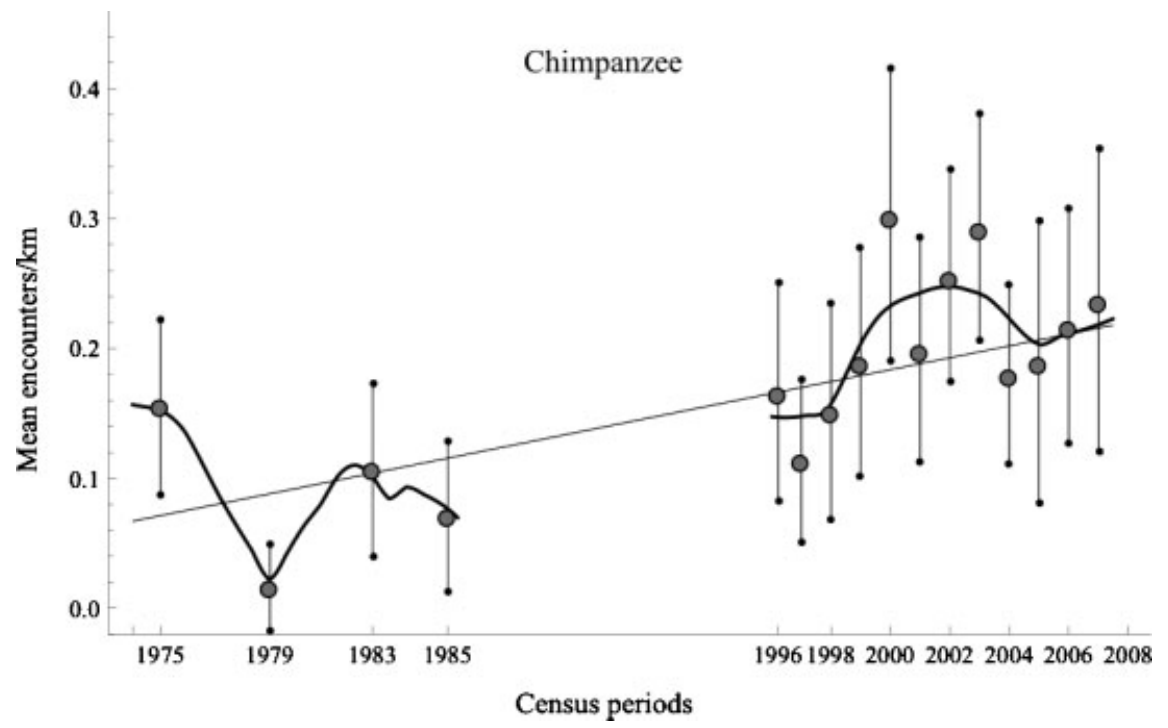

Fig. 2. Chimpanzee population change. Refer to Figure 1.

The increase in encounters with mangabeys was consistent, except for the high encounter rates in the 1985 census period and the low rates in 1996 and 2001 (Fig. 3). We think these deviations simply reflect intercensus variability rather than actual population oscillations, because the differences in encounter rates with the preceding year (1984) or subsequent years (1997 and 2002) were too great to be accounted for by annual recruitment alone. From 2003 through 2007, the increase in mangabey sightings was consistent.

The long-term increase in encounters with redtails was consistent, except for the marginally higher encounter rates in 1998 and 1999 (Fig. 6), a period when one of the redtail groups using the census area divided into two new groups [Windfelder $\&$ Lwanga, 2002]. Encounter rates with redtails were constant or increased from 2002 through 2007.

The remaining four species (l'Hoest, blue, baboon, and black and white colobus) were relatively uncommon, and much of the fluctuation in encounter rates with them (Figs. 4, 5, 7, and 8) was most likely owing to the high variance in encounter rates associated with low population densities and/or large home ranges (e.g. baboons), rather than to real interannual fluctuations in population size. 


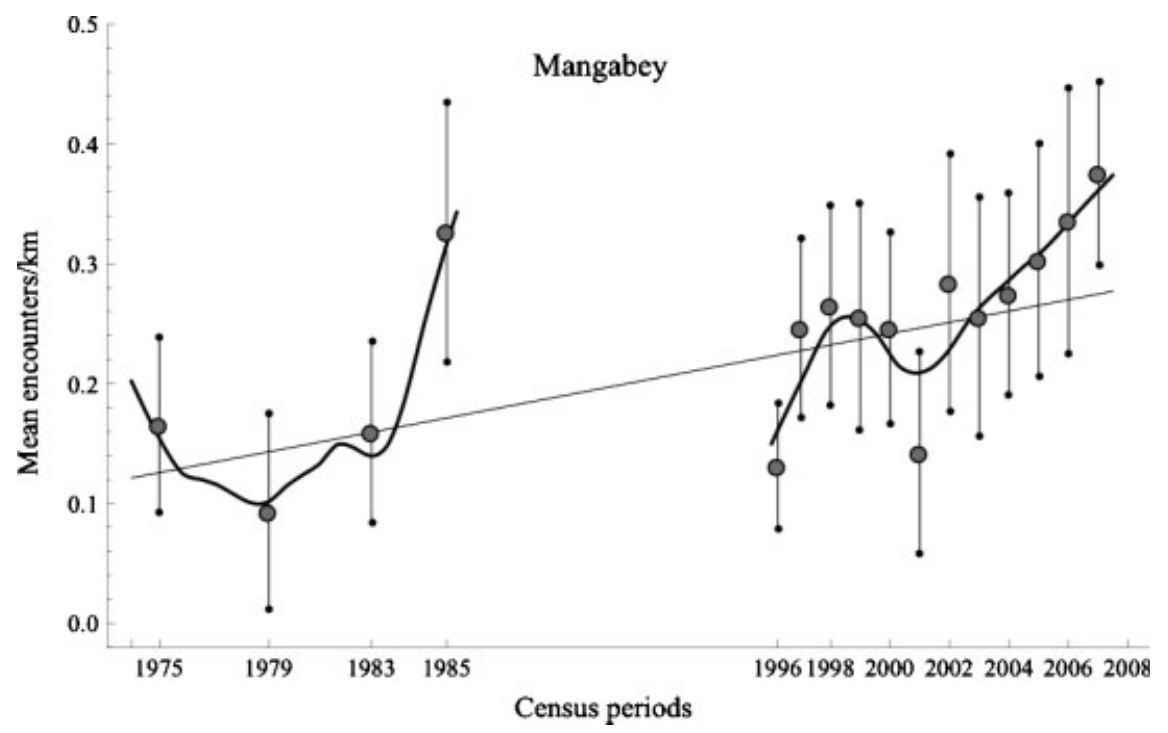

Fig. 3. Mangabey population change. Refer to Figure 1.

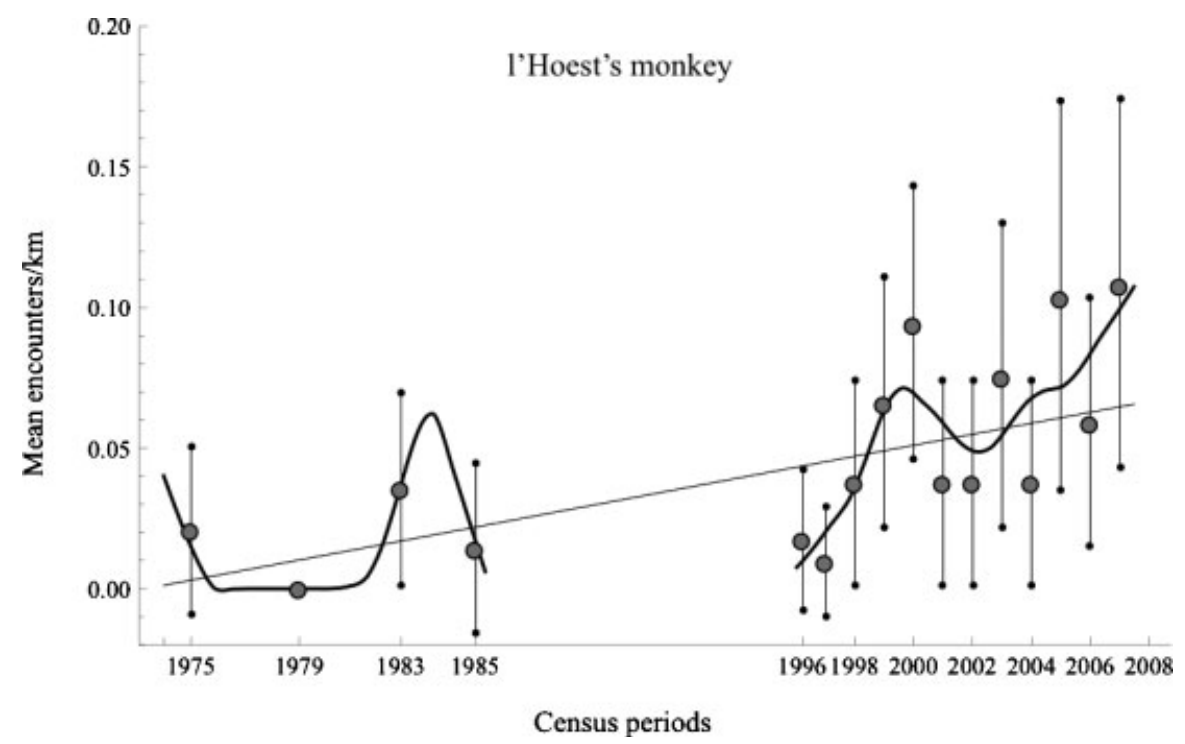

Fig. 4. l'Hoest's monkey population change. Refer to Figure 1.

\section{DISCUSSION}

\section{Red Colobus Decline}

The most obvious change within the Ngogo primate community was the very great and consistent decline in the encounter rates for red colobus. This result is consistent with previous studies. Mitani et al. [2000] compared censuses made in 1975-1976 with those in 1997-1998 and found a statistically significant decline in the number of red colobus groups of approximately 43\%. Twenty-two more censuses along the same transect in 2001 and 2002 indicated a decline in red colobus groups of $86.8 \%$ since the 1975-1976 censuses [Teelen, 2007], but Teelen did not include statistical analyses. Our study not only shows that this decline in sightings of red colobus between the two major census periods (1975-1985 vs. 1996-2007) was highly significant statistically, but it also demonstrates with far greater resolution the temporal pattern of this decline. The decline of red colobus likely occurred over the entire period, although it first became clearly evident in 1985. Thereafter, the decline was consistent without any obvious oscillation or fluctuation between census periods. Furthermore, the decline in sightings of red colobus groups seems to have stopped after 2003 and the encounter rate may have even increased slightly.

To better understand this decline of red colobus, we must determine whether group size changed. Detailed studies of specific red colobus social groups 


\section{4 / Lwanga et al.}

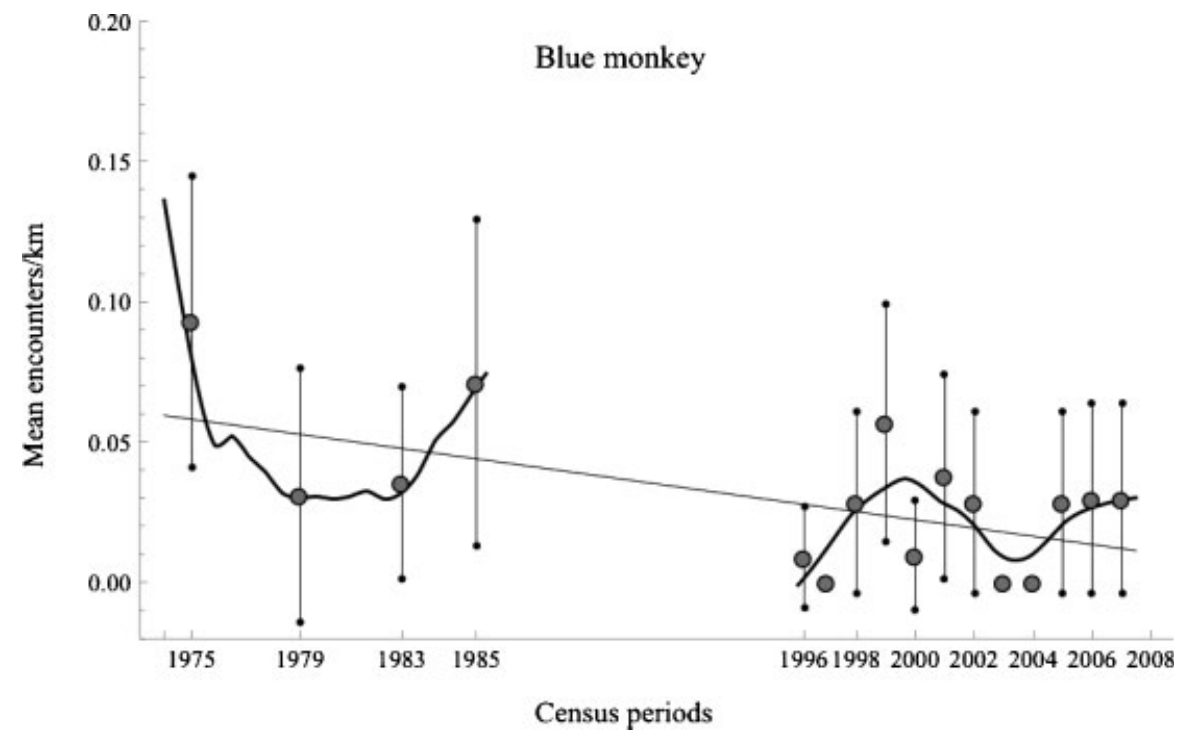

Fig. 5. Blue monkey population change. Refer to Figure 1.

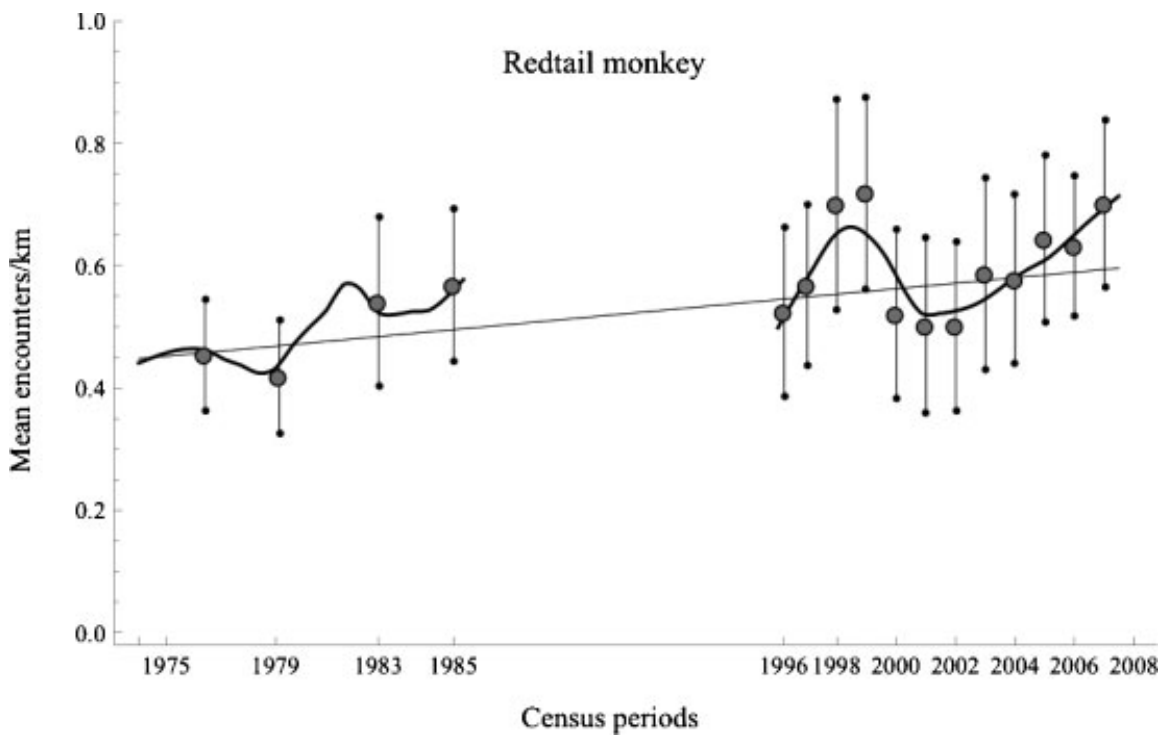

Fig. 6. Redtail monkey population change. Refer to Figure 1.

at Ngogo demonstrated no obvious change in group size over time. In the 1970 s and 1980 s, groups at Ngogo ranging in size from 30 to more than 70 were common [mean of three groups over 5 years was 38.6, range 9.1-75; Struhsaker, 2010, p 290-291], whereas in 2001-2003 the average size of four groups was 39.5 (range 22.3-57.3) [Struhsaker, 2010; Teelen, 2005]. We found no significant difference in red colobus group size between these two study periods $\left(U=5, P=0.86\right.$, two-tailed test, $\left.n_{1}=3, n_{2}=4\right)$, although our samples are small. This is in contrast to the situation at Gombe where Stanford [1998] concluded that predation by chimpanzees resulted in $>50 \%$ decline in the average size of red colobus groups. The constancy of group size at Ngogo most likely resulted from a combination of immigration and fusion of individuals from one or more groups that survived intense predation by chimpanzees [Struhsaker, 2010]. This hypothesis is supported by Teelen [2005] who reported that one of her main red colobus study groups at Ngogo increased by 25 individuals during her 7-month absence between 2001 and 2002. Some members in the larger group were unhabituated to human observers, suggesting that they were new immigrants. Furthermore, during the same study period, Teelen's red colobus group D split into two smaller groups, each of which joined another and different group of red colobus [Teelen, 2005]. Struhsaker [2010] also observed red colobus joining new groups after their own group 


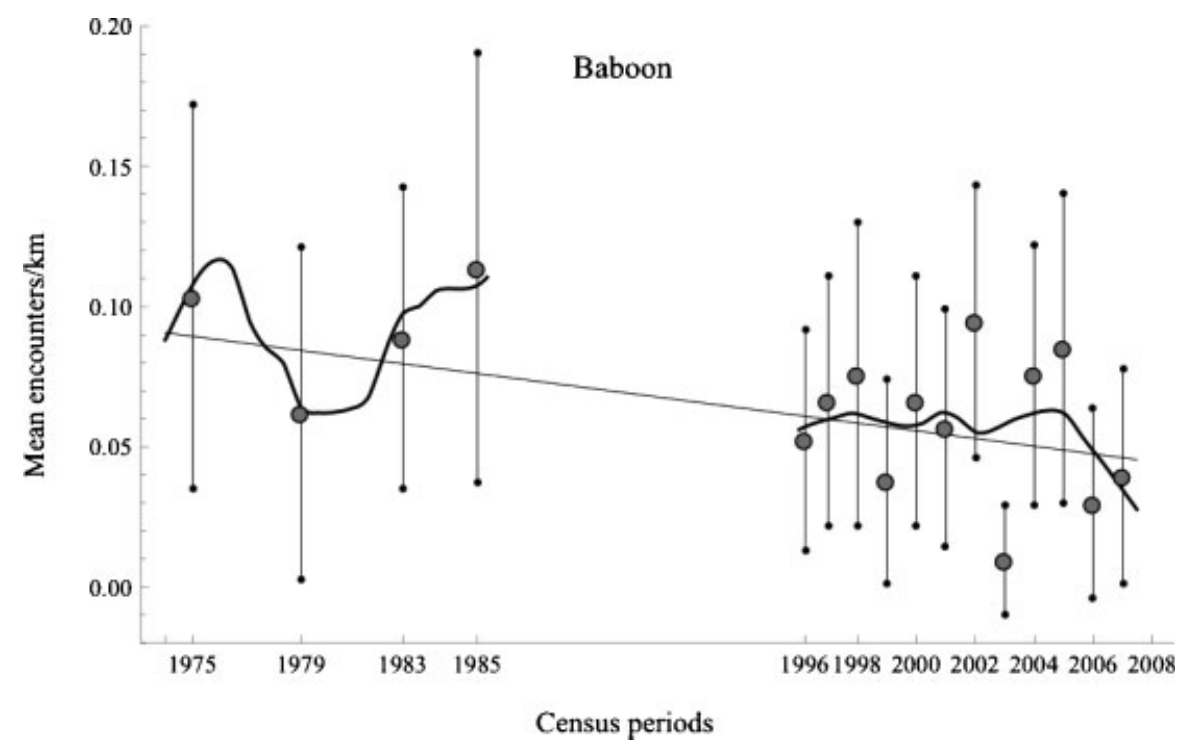

Fig. 7. Baboon population change. Refer to Figure 1.

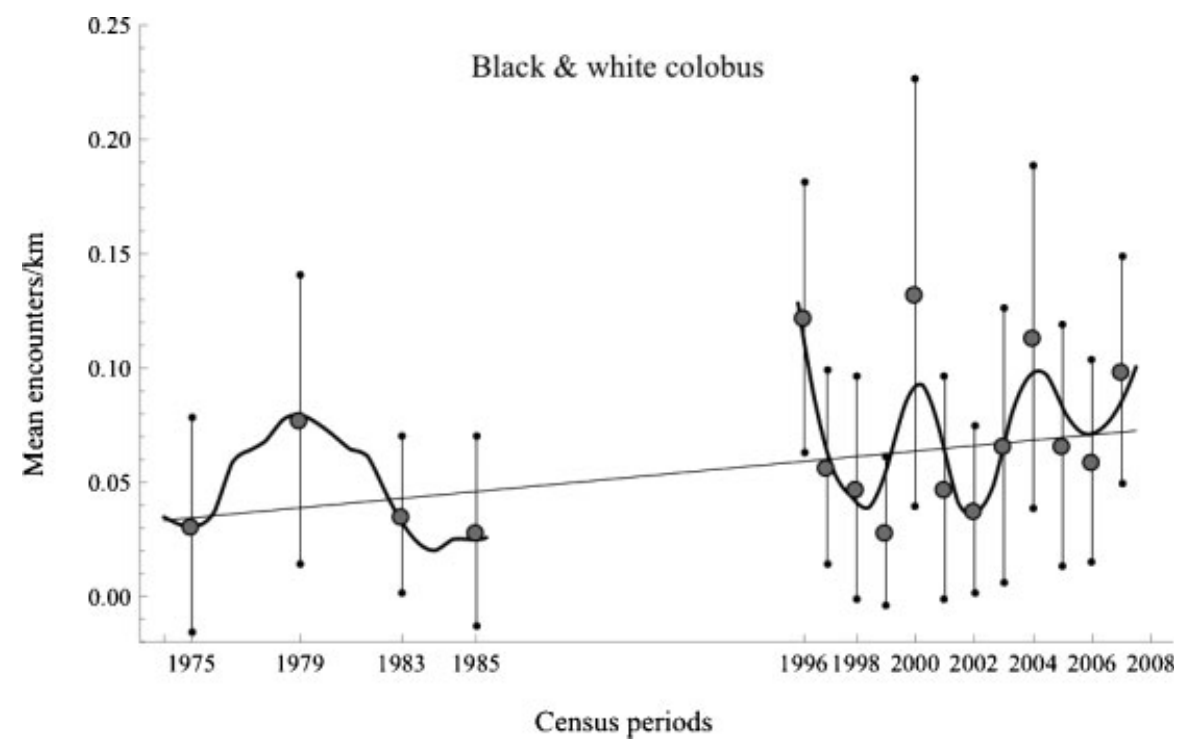

Fig. 8. Black and white colobus population change. Refer to Figure 1.

dissolved. Events like these may explain why group size seems to have remained unchanged at Ngogo while group density declined.

The decline in the Ngogo red colobus population also coincided with changes in their home range size. In 1976-1983, the home range of the main study group was 93 ha [Struhsaker, 2010; p 53]. By contrast, in 2001-2002, the home range size of four red colobus groups varied from 257 to 360 ha [Simone Teelen, personal communication], a 3.3-fold increase. We do not know why home ranges expanded so markedly, but we speculate that red colobus may have been trying to avoid predation by the chimpanzees, using larger home ranges to reduce the predictability of their location at any one time.
Range expansion would have been facilitated by the decline in the number of red colobus groups and the decreased likelihood of intergroup conflicts.

\section{Possible Causes of Red Colobus Population Decline}

A number of factors might have contributed to the decline of red colobus at Ngogo, including disease, predation by crowned eagles (Stephanoaetus coronatus) and chimpanzees, increased interspecific competition, and changes in habitat [Mitani et al., 2000; Struhsaker, 2000, 2008, 2010; Teelen, 2005, 2007]. There is no evidence that red colobus were avoiding the vicinity of this specific census transect 


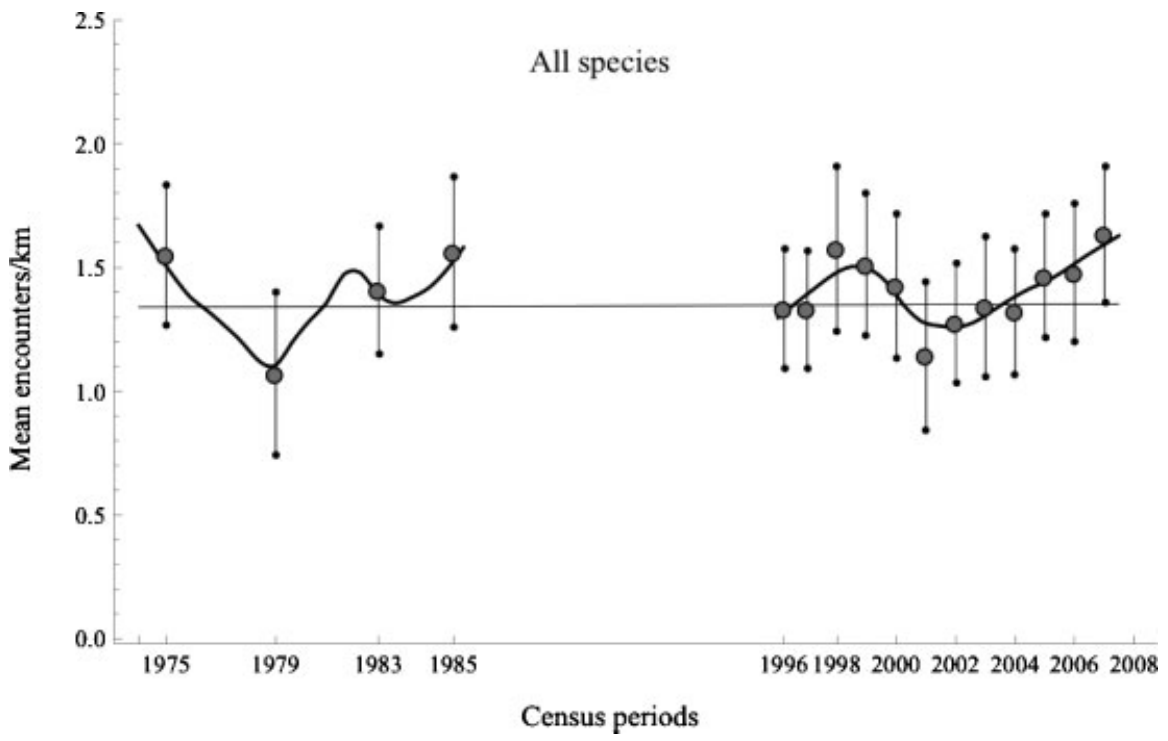

Fig. 9. All species population change. Refer to Figure 1.

as determined by follows of specific red colobus groups, broad surveys (searches) covering the entire study area, and censuses along other transects [Lwanga, 2006; Struhsaker, unpublished data; Teelen, 2005, 2007].

Increased interspecific competition is not likely to have played a major role, because red colobus generally have little dietary overlap with other species and their main potential food competitor (black and white colobus), as suggested by one study conducted $10 \mathrm{~km}$ north of Ngogo [Chapman \& Pavelka, 2005], occurred at relatively low densities in the transect area [Struhsaker, 1978, 2010]. In support of this conclusion, we found no significant correlation between the sighting frequencies of red colobus and black and white colobus $\left(r_{\mathrm{s}}=0.0094\right.$, $P=0.43$, one-tail, $n=372$ ), i.e. sightings of black and white colobus did not increase as those of red colobus decreased.

Although disease may have contributed to some of the decline, we think it played a lesser role compared with that of predation, because only some of the adult males and none of the adult females or juveniles apparently died from disease. All these possible deaths from disease occurred before 1984 [Struhsaker, 2000, 2008, 2010]. Furthermore, although red colobus at Kibale (Kanyawara) are known hosts to a number of parasites and viruses, none of these caused obvious illness [Gillespie et al., 2005; Goldberg et al., 2008].

Teelen [2007] concluded that changes in forest composition at Ngogo, reported by Lwanga et al. [2000] between 1975 and 1998, could not account for the rapid decline in red colobus. Teelen's [2007] study did not, however, provide dietary data for the Ngogo red colobus. We, therefore, evaluated Struhsaker's [2010] dietary data for the red colobus at Ngogo relative to the forest changes there [Lwanga et al., 2000], to determine if there were appreciable declines in food species that might have contributed to the red colobus decline. Sixteen tree species accounted for $79 \%$ of the total diet over 8 years [1976-1983, Struhsaker, 2010]. Only 8 of these 16 species were sufficiently numerous ( $>20$ individuals) in the enumeration to permit statistical analysis of change by Lwanga et al. [2000]. Among these eight food tree species, five showed no significant change in density over the 23-year period, whereas one increased and only two decreased (by only 2\%). Those six species with either no change or that increased accounted for $30.6 \%$ of the red colobus diet from 1976-1983, whereas those two species that decreased by $2 \%$ accounted for only 9.9\% of the diet [Struhsaker, 2010], i.e a reduction from 9.9 to $9.7 \%$ in potential food. Furthermore, although red colobus are generally much more abundant in old-growth forest than in young colonizing forest, they do use young forest at Ngogo [Lwanga, 2006]. Consequently, the colonizing forest that developed after 1991 in the grassland near the census transect provides potential food resources that could compensate for any reduction of red colobus food in the old-growth forest. Based on these results, we agree with Teelen [2007] that forest dynamics and changes in the food supply were not obvious or major causes of the dramatic decline in red colobus at Ngogo. Consistent with this conclusion is the fact that we observed no signs of malnutrition or starvation in any red colobus at Ngogo [Lwanga \& Struhsaker, unpublished observation]. Estimated changes in food supply were also unable to explain long-term population dynamics of red colobus further north in Kibale at Kanyawara where group densities remained stable despite increases in the cumulative dbh of their food trees [Chapman et al., 2010]. 
Annual offtake of red colobus owing to predation by crowned eagles at Kanyawara and Ngogo in Kibale was estimated to be approximately $0.5-2 \%$ of these populations [Mitani et al., 2001; Struhsaker, 2010; Struhsaker \& Leakey, 1990]. This is a low rate compared with the offtake owing to predation by chimpanzees at Ngogo (see below) and low compared with the annual reproductive output (natality) of red colobus [approximately 11-16.5\%; Struhsaker, 2010]. Similarly, low rates of predation by crowned eagles on red colobus were found at Tai [Shultz et al., 2004; Shultz \& Thomsett, 2007]. We conclude that predation by crowned eagles cannot explain the drastic decline of red colobus at Ngogo.

As first proposed by Mitani et al. [2000], and in agreement with Lwanga [2006] and Teelen [2007], we conclude that predation by chimpanzees is the most obvious and likely explanation for the decline of red colobus at Ngogo. Watts and Mitani [2002] and Teelen [2007, 2008] estimated that the number of red colobus killed per year at Ngogo by chimpanzees ranged from 167 in the period of 1995-1998 to 322 in 2002 , representing approximately $15-53 \%$ of the red colobus population, depending on the year [Teelen, 2007, 2008]. We agree with Teelen [2007, 2008] that this unsustainable level of predation was likely the consequence of the extremely large community of chimpanzees at Ngogo. In 1999, this community contained at least 146 individuals, including 24 adult males and 15 adolescent males, the 2 age classes accounting for $98 \%$ of the kills, making it the largest known community of chimpanzees [Watts \& Mitani, 2002]. Chimpanzee hunting parties at Ngogo were extremely successful, killing red colobus in at least $75 \%$ of their attempts and killing as many as 8 infants and 13 individuals in a single attack [Watts \& Mitani, 2002]. The negative correlation we found in census encounter rates between chimpanzees and red colobus is consistent with the preceding data.

Before 1996, only one possible case of predation by chimpanzees on red colobus was observed. During $488 \mathrm{hr}$ of observing chimpanzees between December 1976 and May 1981, Ghiglieri [1984] once observed an adult male carry and nibble meat from a skin that appeared to be that of a red colobus. The very high rates of predation on red colobus by chimpanzees from 1996 onward suggest that rates of predation may have increased. We emphasize, however, that the chimpanzees at Ngogo were not well habituated until the late 1980s and early 1990s. Consequently, predation rates by them before habituation may have been underestimated.

That predation by chimpanzees was the most likely cause of the Ngogo red colobus decline is further supported by demographic changes that occurred in these red colobus. Struhsaker [2010] found that both the ratios of infants per adult female and subadults plus juveniles per adult female were significantly lower in the Ngogo red colobus during
2001-2003 than they were in 1978-1983. These young age classes were most heavily preyed upon by chimpanzees. At Ngogo, 30-35\% of the red colobus killed by chimpanzees were infants and $29-30 \%$ were subadults and juveniles [Mitani \& Watts, 1999; Watts \& Mitani, 2002], more than twice the proportional representation of these age classes in red colobus groups [Teelen, 2005]. This level of predation and age-based selectivity by chimpanzees on the Ngogo red colobus has a negative impact on recruitment and population size.

We emphasize that the Ngogo study is the only one to our knowledge providing strong evidence that predation other than by humans has resulted in a pronounced decline in the population of a nonhuman primate species. Furthermore, it is also the only documented case in which predation by one nonhuman primate species is the most likely explanation for the population decline of another.

\section{Apparent Growth of the Ngogo Chimpanzee Community}

From 1999 onward, the long-term census data indicate that encounters with chimpanzee parties along the main census transect increased significantly ( $\sim 53 \%$ from 1975 to 2007 ). The chimpanzee fusion-fission social system and the very large size of their home range may partly explain some of the interannual variation in the number of chimpanzee parties seen during the censuses. However, we have no evidence to suggest that census encounter rates with chimpanzees increased over time, because of a decrease in chimpanzee party size and a corresponding increase in numbers of parties or because they increased their use of the transect area [Mitani, unpublished data].

Based on a combination of recognizable individuals, ranging data, nest counts, and line transect data collected during 23 months between December 1976 and March 1981, Ghiglieri [1984] estimated that the Ngogo chimpanzees numbered approximately 55 individuals with a home range of $23.1-37.9 \mathrm{~km}^{2}$. By 1999 , at least 146 known chimpanzees were in the Ngogo community [Watts \& Mitani, 2002] occupying an area of $>28 \mathrm{~km}^{2}$ [Mitani et al., 2010]. Although this comparison supports the conclusion that the chimpanzees have increased in abundance at Ngogo, one cannot ignore the possible effects of methodological differences between the two studies. The most accurate method of determining chimpanzee community size is achieved by individual recognition of all members of the community. This, however, takes many years to accomplish because of the diffuse nature of the fission-fusion social system, the enormous home range, immigration and emigration, and, in the case of Ngogo, the very large size of the community [e.g. Boesch \& Boesch-Achermann, 2000; Mitani, unpublished data]. 
Although the long-term census data indicate an increase in encounter rate with chimpanzee parties, we shall never know with certainty the extent to which the number of chimpanzees increased during these 32.9 years or why they increased.

\section{Long-Term Future of Ngogo Red Colobus}

The impact of predation by chimpanzees on the red colobus at Ngogo represents an unusual situation involving two species of conservation concern in which one is having a negative impact on the other. The Ngogo red colobus may not be the only population negatively affected by chimpanzee predation. Possible examples have been described for Gombe [Stanford, 1998] and Tai [Boesch \& BoeschAchermann, 2000]. Although Stanford [1998] demonstrated a decline in red colobus group size that could have been due to predation by chimpanzees, neither of these two studies gave data showing declines in red colobus populations. However, the absence of red colobus from all forests of western Uganda, except Kibale, might result from the combined effect of predation by humans and chimpanzees [Struhsaker, 1999].

Although it is unclear how the relationship between red colobus and chimpanzees at Ngogo will develop, as the red colobus population declined, the chimpanzee community there expanded its territory and took over part of the range of another chimpanzee community to the northeast. This expansion resulted in a $22.3 \%$ increase in their territory size [Mitani et al., 2010] where they preyed upon red colobus [Mitani, unpublished observation]. This range expansion, in turn, may result in decreased predation on red colobus in the central portion of the Ngogo chimpanzee territory. Furthermore, because (1) Kibale is a relatively large forest $\left(766 \mathrm{~km}^{2}\right)$, (2) Ngogo is located near the center of this forest, and (3) female red colobus disperse from their natal groups [Struhsaker, 1975, 2010], ample opportunity exists for red colobus to disperse into the Ngogo area. Consequently, the Ngogo red colobus population has the potential to recover.

\section{Mangabey Increase}

The significant increase in sightings of mangabeys is consistent with the fission of the main Ngogo study group of mangabeys in the early 1980s [Lysa Leland, personal communication; Struhsaker \& Leland, 1988]. This division into two groups resulted in a $\sim 25 \%$ increase in the number of mangabey groups using the census area. Mangabey group size seemed to remain relatively constant between 1974 and 1998 [Mitani et al., 2000] ( $n=3$ groups and $\sim 50 \%$ of those using census area). Consequently, the increase in groups encountered was not likely the result of groups simply dividing into more, but smaller groups. Lwanga [2006] found that mangabeys were sometimes as common in patches of young colonizing forest as they were in adjacent old-growth forest. As explained in the methods section, the $\sim 50$ ha grassland encircled by the census transect was completely colonized by young forest during the course of our studies. This forest regeneration resulted in more potential habitat for mangabeys and may have contributed to their increase. However, further north in Kibale, Chapman et al. [2010] found that over periods spanning 26-36 years, the density of mangabey groups increased even though the cumulative dbh of their food trees remained unchanged.

\section{Redtail Increase}

The increase in sightings of redtails, like the mangabeys, was associated with at least two group fissons of the main study group of redtails at Ngogo between 1980 and 1998 [Struhsaker \& Leland, 1988; Windfelder \& Lwanga, 2002]. These groups used the census area along with at least five other redtail groups. Consequently, the group fissions increased the number of redtail groups using the census area by $\sim 40 \%$. Average group size remained unchanged over this same period $(U=6, P=1.14$, two-tailed, $n_{1}=3, n_{2}=5$ [Mitani et al., 2000; Struhsaker, 1988; Windfelder \& Lwanga, 2002]). Lwanga [2006] found that redtails at Ngogo are sometimes much more abundant in colonizing forest. The forest regeneration in the grassland near the census transect, referred to earlier, resulted in more habitat for redtails and may have facilitated their increase.

\section{Black and White Colobus Increase}

The black and white colobus at Ngogo occur in higher densities in young colonizing forest than in old-growth forest [Lwanga, 2006]. This habitat selectivity may account for the increase in sightings of black and white colobus along our census transect because, as suggested for the mangabeys and redtails, forest regeneration in the nearby grassland provided more potential habitat for them.

\section{L'Hoest Increase}

Interpretation of the increase in sighting frequency of l'Hoest's monkeys is confounded by two factors. The first is the low density of this species and the corresponding variability in sighting frequency. Second, this species spends most of its time on or near the ground, often in very dense vegetation. Unhabituated groups flee quietly on the ground from humans and are, therefore, more difficult to detect. We suggest that at least some of the increase in sighting frequency of l'Hoest's monkey groups over this 32.9-year period might be due to increased habituation. Furthermore, because this species is often found in dense vegetation, its use of the area 
near the census transect may have increased as the nearby grassland reverted to thicket and young dense forest. Consistent with this idea is Lwanga's [2006] finding that l'Hoest's monkey is sometimes more abundant in colonizing forest than it is in oldgrowth forest.

\section{Baboon Decline}

In contrast to the preceding four species, the use of the census area by baboons may have decreased because the nearby grassland, a more preferred habitat for them, was replaced by thicket and young forest. Although we have no direct evidence, this loss of habitat may explain the decline in baboon sightings.

\section{Blue Monkey Decline}

We do not know why the sightings of blue monkey groups declined, but this occurred as early as 1997-1998 [Mitani et al., 2000]. Fruit production at Ngogo affords what seemed to be excellent habitat for them [Butynski, 1990]. The main study group of blues at Ngogo fissioned in 1984. One of the two daughter groups left the Ngogo study area, whereas the other greatly expanded and shifted its home range away from the census area [Butynski, 1990; Lwanga, 1987]. Butynski [1990] found no support for the food competition hypothesis and suggested that the blue monkey population at Ngogo crashed, possibly because of disease or human hunting, sometime before the first censuses in 1975. There is no evidence that disease or hunting has affected the Ngogo blue monkeys since 1975 [Butynski, 1990; Lwanga \& Struhsaker, personal observation], yet encounter rates with blue groups along the transect continued to decline [Lwanga, 2006; Mitani et al., 2000; Teelen, 2007, this study]. Contrary to Butynski [1990], Lwanga [1987] concluded that the low population of blues at Ngogo could be due to interspecific food competition, particularly from mangabeys, redtails, and chimpanzees, all of whom increased during this 32.9-year period. Lwanga [1987] based this conclusion on the following facts. After the group fission, the blue monkey group that remained in the study area expanded its range and stopped using a very large portion of the previous range, including that near the census transect. This new area had significantly greater densities of the 20 most important food tree species for blues than did the old area that was no longer used. Furthermore, blue monkeys were in association with redtails and mangabeys significantly less in this new area than they were in the old unused area before the fission. Coincident with the blue monkey group fission and range shift was the fission of a redtail group and a mangabey group in the area that the blues vacated and no longer used after the fission. Because blues have considerable dietary overlap with redtails and mangabeys [Butynski, 1990; Lwanga, 1987; Struhsaker, 1978], Lwanga [1987] concluded that the blue group shifted its range to reduce interspecific competition for food from the expanding populations of redtails and mangabeys. Interspecific competition for food might also partly explain the decline in density of blue monkey groups at Kanyawara, Kibale, where estimates of their food supplies remained unchanged, but group densities of a potential competitor (mangabeys) increased [Chapman et al., 2010]. Although the encounter rates with blue monkey groups declined in our census transect area, there is evidence that group size and, therefore, total numbers of blue monkeys in other parts of the Ngogo study area have increased between 1983-1984 and 2009, perhaps by as much as two-fold [Angedakin \& Lwanga, unpublished data].

\section{Group Encounters Regardless of Species}

Although encounter rates varied over time for each of the eight species, group encounter rates for all species combined did not. This result does not necessarily mean that the numerical abundance or biomass of primates remained constant in the census area because red colobus groups, the species that declined the most, were usually larger than those of the other species. One would require greater detail on group size and biomass of the other species to assess changes in primate abundance and biomass. Nevertheless, it seems clear that the Ngogo primate community is in a nonequilibrium state, having changed from one that was dominated by a folivore (red colobus) and a frugivorous omnivore (redtail) to one dominated by three species of frugivorous omnivores (redtail, mangabey, and chimpanzee). One way of portraying this shift in species composition is to compare the average proportion of groups encountered during the 1975-1976 census period with those in the 2007 period. In $1975-1976,34 \%$ of the groups encountered were red colobus and $29 \%$ were redtails, whereas in $2007,43 \%$ were redtails, $23 \%$ mangabeys, and $15 \%$ chimpanzees. A nonequilibrium state has also been described for the primates at Kanyawara, Kibale [Chapman et al., 2010], and may prove to be widespread in other tropical forests, as in other ecosystems [e.g. Sinclair \& Byrom, 2006].

The results presented here demonstrate the value of long-term, continuous monitoring using the transect census method as a means of understanding the dynamics and intrinsic threats to primate populations. This kind of monitoring is critical for the development of conservation management plans and models of population and community ecology. One important lesson from this study is that very large areas of forest must be protected in order to protect all species from the effects of nonequilibrium dynamics. 


\section{NOTE ADDED IN PROOF}

Corrections were made after initial online publication to the following sections: Page 11 (right column, line 24); Page 14 (right column, line 26).

\section{ACKNOWLEDGMENTS}

This article is dedicated to the memory of Simone Teelen whose research contributed greatly to our understanding of the primate community dynamics at Ngogo, a place she dearly loved. A kind and dedicated person, she is missed by all who knew her.

Dr. David Watts and the North Carolina Zoo are thanked for supporting the long-term census studies of Lwanga at Ngogo. The 1975-1985 censuses were supported in part by the New York Zoological Society and the African Wildlife Foundation. Those conducted from 1996-2007 were supported by U.S. National Science Foundation grants (SBR-9253590, BCS-0215622, IOB-0516644) to Mitani. Permission to conduct research in Kibale was given by the Uganda National Council for Science and Technology, Uganda Forest Department, Uganda Wildlife Authority, and the Makerere University Biological Field Station. We extend our thanks to all these institutions. Our study complied with all animal care regulations and national laws in Uganda. The research was also approved by the University Committee on the Use and Care of Animals (UCUCA), University of Michigan under UCUCA Research Applications 6793A, 7472, 8436, and 9035.

\section{REFERENCES}

Boesch C, Boesch-Achermann H. 2000. The chimpanzees of the Tai Forest: behavioural ecology and evolution. Oxford: Oxford University Press. 316p.

Buckland ST, Plumptre AJ, Thomas L, Rexstad EA. 2010. Line transect sampling of primates: can animal-to-observer distance methods work? International Journal of Primatology 31:485-499.

Butynski TM. 1990. Comparative ecology of blue monkeys (Cercopithecus mitis) in high- and low-density subpopulations. Ecological Monographs 60:1-26.

Caughley G. 1980. Analysis of vertebrate populations. Chichester, NY/Brisbane, Toronto: Wiley. 234p.

Chapman CA, Pavelka MSM. 2005. Group size in folivorous primates: ecological constraints and the possible influence of social factors. Primates 46:1-9.

Chapman CA, Balcomb SR, Gillespie TR, Skorupa JP, Struhsaker TT. 2000. Long-term effects of logging on African primate communities: a 28 year comparison from Kibale National Park, Uganda. Conservation Biology 14:207-217.

Chapman CA, Struhsaker TT, Skorupa JP, Snaith TV, Rothman JA. 2010. Understanding long-term primate community dynamics: implications of forest change. Ecological Applications 20:179-191.

Ferrari SF, Chagas RRD, Souza-Alves JP. 2010. Line transect surveying of arboreal monkeys: problems of group size and spread in a highly fragmented landscape. American Journal of Primatology 71:1-8.

Ghiglieri M. 1984. The chimpanzees of Kibale Forest. New York: Columbia University Press. 226p.
Gillespie TR, Greiner EC, Chapman CA. 2005. Gastrointestinal parasites of the colobus monkeys of Uganda. Journal of Parasitology 9:569-573.

Goldberg TL, Chapman CA, Cameron K, Saj T, Karesh WB, Wolfe ND, Wong WS, Dubois ME, Slifka MK. 2008. Serological evidence for novel poxvirus in endangered red colobus monkeys, Western Uganda. Emerging Infectious Diseases 14:801-803.

Kachigan SK. 1986. Statistical analysis: an interdisciplinary introduction to univariate and multivariate methods. New York: Radius Press. 589p.

Kuhl H, Maisels F, Ancrenaz M, Williamson EA. 2008. Best practice guidelines for surveys and monitoring of great ape populations. Gland, Switzerland: IUCN SSC Primate Specialist Group. 32p.

Lwanga JS. 1987. Group fission in blue monkeys, (Cercopithecus mitis stuhlmanni): effects on socioecology in Kibale Forest, Uganda [dissertation]. Makerere University, Kampala, Uganda. 171p.

Lwanga JS. 2003. Forest succession in Kibale National Park, Uganda: implications for forest restoration and management. African Journal of Ecology 41:9-22.

Lwanga JS. 2006. Spatial distribution of primates in a mosaic of colonizing and old growth forest at Ngogo, Kibale National Park, Uganda. Primates 47:230-238.

Lwanga JS, Butynski TM, Struhsaker TT. 2000. Tree population dynamics in Kibale National Park, Uganda 1975-1998. African Journal of Ecology 38:238-247.

Marshall AR, Lovett JC, White PCL. 2008. Selection of linetransect methods for estimating the density of group-living animals: lessons from the primates. American Journal of Primatology 70:452-462.

Mbora DNM, Meikle DB. 2004. Forest fragmentation and the distribution, abundance and conservation of the Tana River red colobus (Procolobus rufomitratus). Biological Conservation 118:67-77.

McGraw WS. 2007. Vulnerability and conservation of the Tai monkey fauna. In: McGraw WS, Zuberbuhler K, Noe R, editors. Monkeys of the Tai Forest: an African primate community. Cambridge: Cambridge University Press. p 290-316.

Mitani JC, Watts DP. 1999. Demographic influences on the hunting behavior of chimpanzees. American Journal of Physical Anthropology 109:439-454.

Mitani JC, Struhsaker TT, Lwanga JS. 2000. Primate community dynamics in old growth forest over 23.5 years at Ngogo, Kibale National Park, Uganda: implications for conservation and census methods. International Journal of Primatology 21:269-286.

Mitani JC, Sanders WJ, Lwanga JS, Windfelder TL. 2001. Predatory behavior of crowned hawk-eagles (Stephanoaetus coronatus) in Kibale National Park, Uganda. Behavioral Ecology and Sociobiology 49:187-195.

Mitani JC, Watts DP, Amsler SJ. 2010. Lethal intergroup aggression leads to territorial expansion in wild chimpanzees. Current Biology 20:507-508.

National Research Council. 1981. Techniques for the study of primate population ecology. Washington, DC: National Academy Press. 233p.

Oates JF, Abedi-Lartey M, McGraw WS, Struhsaker TT, Whitesides G. 2000. Extinction of a west African red colobus monkey. Conservation Biology 14:1526-1532.

Pope TR. 1998. Effects of demographic change on group kin structure and gene dynamics of populations of red howling monkeys. Journal of Mammalogy 79:692-712.

Rovero F, Struhsaker TT. 2007. Vegetative predictors of primate abundance: utility and limitations of a fine-scale analysis. American Journal of Primatology 69:1242-1256.

Rudran R, Fernandex-Duque E. 2003. Demographic changes over thirty years in a red howler population in Venezuela. International Journal of Primatology 24:925-947. 
Ruskeepää H. 2009. Mathematica navigator: mathematics, statistics, and graphics. 3rd ed. Burlington, MA: Academic Press. 1111p.

Shultz S, Thomsett S. 2007. Interactions between African crowned eagles and their prey community. In: McGraw WS, Zuberbuhler K, Noe R, editors. Monkeys of the Tai Forest: an African primate community. Cambridge: Cambridge University Press. p 171-193.

Shultz S, Noe R, McGraw WS, Dunbar RIM. 2004. A community-level evaluation of the impact of prey behavioural and ecological characteristics on predator diet composition. Proceedings of the Royal Society of London B 271:725-732.

Sinclair ARE, Byrom AE. 2006. Understanding ecosystem dynamics for conservation. Journal of Animal Ecology 75:64-79.

Sokal RR, Rohlf FJ. 1995. Biometry, 3d ed. New York: WH Freeman and Company. 887p.

Stanford CB. 1998. Chimpanzee and red colobus: the ecology of predator and prey. Cambridge, MA: Harvard University. $296 \mathrm{p}$.

Struhsaker TT. 1975. The red colobus monkey. Chicago: University of Chicago Press. 311p.

Struhsaker TT. 1978. Food habits of five monkey species in the Kibale Forest, Uganda. In: Chivers DJ, Herbert J, editors. Recent advances in primatology, vol. 1, behaviour. London: Academic Press. p 225-247.

Struhsaker TT. 1988. Male tenure, multi-male influxes, and reproductive success in redtail monkeys (Cercopithecus ascanius). In: Gautier-Hion A, Bourliere F, Gautier J-P, Kingdon J, editors. A primate radiation: evolutionary biology of the African guenons. Cambridge: Cambridge University Press. p 340-363.

Struhsaker TT. 1997. Ecology of an African rain forest: logging in Kibale and the conflict between conservation and exploitation. Gainesville: University Press of Florida. 434p.

Struhsaker TT. 1999. Primate communities in Africa: the consequence of long-term evolution or artifact of recent hunting? In: Fleagle JG, Janson CH, Reed KE, editors. Primate communities. Cambridge: Cambridge University Press. p 289-294.

Struhsaker TT. 2000. Variation in adult sex ratios of red colobus monkey social groups: implications for interspecific comparisons. In: Kappeler PM, editor. Primate males: causes and consequences of variation in group composition. Cambridge: Cambridge University Press. p 108-119.

Struhsaker TT. 2002. Guidelines for biological monitoring and research in Africa's rain forest protected areas. A report to the Center for Applied Biodiversity Science, Conservation International. 55p.
Struhsaker TT. 2005. Conservation of red colobus and their habitats. International Journal of Primatology 26:525-538.

Struhsaker TT. 2008. Demographic variability in monkeys: implications for theory and conservation. International Journal of Primatology 29:19-34.

Struhsaker TT. 2010. The red colobus monkeys: variation in demography, behavior, and ecology of endangered species. Oxford and New York: Oxford University Press. 349p.

Struhsaker TT, Leakey M. 1990. Prey selectivity by crowned hawk-eagles on monkeys in the Kibale forest, Uganda. Behavioral Ecology and Sociobiology 26:435-443.

Struhsaker TT, Leland L. 1988. Group fission in redtail monkeys (Cercopithecus ascanius) in the Kibale forest, Uganda. In: Gautier-Hion A, Bourliere F, Gautier J-P, Kingdon J, editors. A primate radiation: evolutionary biology of the African guenons. Cambridge: Cambridge University Press. p 364-388.

Struhsaker TT, Oates JF. 1995. The biodiversity crisis in southwestern Ghana. African Primates 1:5-6.

Struhsaker TT, Marshall AR, Detwiler K, Siex K, Ehardt C, Dahl Lisbjerg D, Butynski TM. 2004. Demographic variation among Udzungwa red colobus in relation to gross ecological and sociological parameters. International Journal of Primatology 25:615-658.

Teelen S. 2005. The impact of hunting by chimpanzees (Pan troglodytes) on demography and behavior of red colobus monkeys (Procolobus ruformitratus) at Ngogo, Kibale National Park, Uganda [Dissertation]. Yale University, New Haven, CT. 151p. Available from: UMI; AAT 3169000.

Teelen S. 2007. Influence of chimpanzee predation on associations between red colobus and red-tailed monkeys at Ngogo, Kibale National Park, Uganda. International Journal of Primatology 28:593-606.

Teelen S. 2008. Influence of chimpanzee predation on the red colobus population at Ngogo, Kibale National Park, Uganda. Primates 49:41-49.

Watts DP, Mitani JC. 2002. Hunting behavior of chimpanzees at Ngogo, Kibale National Park, Uganda. International Journal of Primatology 23:1-28.

Whitesides GH, Oates JF, Green SM, Kluberdanz RP. 1988. Estimating primate densities from transects in a west African rain forest: a comparison of techniques. Journal of Animal Ecology 57:345-367.

Windfelder TL, Lwanga JS. 2002. Group fission in red-tailed monkeys (Cercopithecus ascanius) in Kibale National Park, Uganda. In: Glenn ME, Cords M, editors. The guenons: diversity and adaptation in African monkeys. New York: Kluwer Academic/Plenum Publishers. p 147-159. 